
3 Research Square
Preprints are preliminary reports that have not undergone peer review.
They should not be considered conclusive, used to inform clinical practice, or referenced by the media as validated information.

\title{
Mental Health Impacts for International Students During the COVID-19 Pandemic in China
}

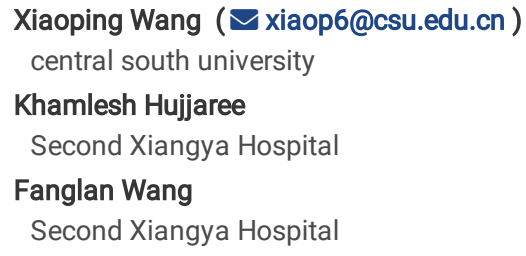

\section{Research}

Keywords: COVID-19, international students, depression, anxiety, PHQ-9, GAD-7هState-Trait Anxiety Inventory

Posted Date: July 29th, 2020

DOI: https://doi.org/10.21203/rs.3.rs-49168/v1

License: () (i) This work is licensed under a Creative Commons Attribution 4.0 International License. Read Full License 


\section{Abstract}

The outbreak of Coronavirus disease 2019 (COVID-19), has led to the quarantine of many residents in their homes worldwide. Some of these people might develop mental health problems, and many solutions have been put in place to address the mental health issues of patients and health professionals affected by the disease. However, not much attention has been given to international students studying in China. The present study aims to conduct an online survey to investigate the mental health status of international students from Changsha city, China.

Materials and Methods: A WeChat-based survey program comprised of questions on demographic information gender, grade year, duration and status of quarantine, duration of sleep, worries about graduation, being able to go to school and presence or absence of a sense of security; as well as questions from the Patient Health Questionnaire-9 (PHQ-9), Generalized Anxiety Disorder-7 (GAD-7) scale and State-Trait Anxiety Inventory(STAI).

Results: The prevalence of depression was $59.4 \%$ and the prevalence of anxiety was $37.8 \%$. The STAI-Y1 STATE scores had a mean value (mean) of 41.42 , standard deviation (S.D) of 10.89 and STAI-Y2 TRAIT scores had a mean value (mean) of 41.85 , standard deviation (S.D) of 11.13 . The risk factors of anxiety or depression were Sleep duration, worrying about graduation in varying degrees, School time, and feeling secure in varying degrees. Higher the Patient Health Questionnaire-9 score and higher Generalized Anxiety Disorder-7 score and higher STAI-Y1 STATE scores were associated with higher STAI-Y2 TRAIT scores.

Conclusion: The present study implies that the university needs to consider planning for acute and long-term psychological help services for international students.

\section{Background:}

New coronary pneumonia - COVID-19 has turned out to be a world public health emergency. By late December 2019, it grew to become clear that a novel Coronavirus was spreading through Wuhan, the capital of Hubei province in China.[1] A group of sufferers who had been exposed to the virus exhibited signs and symptoms of fever, dyspnea, and extreme pneumonia.[2]. Numbers of recognized cases and deaths from COVID-19 have been greater in Wuhan than in any other city in the early stage of the outbreak; and containment, with travel restrictions, was first implemented in that city.[3] The disorder unfolded unexpectedly throughout all the Chinese provinces within a few days due to numerous reasons including 1) the local authorities did not know that the sickness had the characteristic of human-to-human transmission and, 2) it was the opening of China's Spring Festival tour rush and nearby college students had been all leaving for the holidays. [4]

It is properly acknowledged that calamities such as natural disasters and man-made traumas can have a sizeable mental health impact and can end-result in stipulations such as post-traumatic stress disease (PTSD) and depression.[5], [6]. Further, little is recognized about the incidence and danger elements for mental health problems when confronted with such stressors. Different groups of humans from the regular public to students of an international university will have various ranges of psychological issues such as fear, worry, anxiousness, and depression. University students are dealing with a range of challenges in the wake of the COVID-19 outbreak. The pandemic has been escalating and threatening the welfare of human beings globally, and this public fitness emergency generates concern and leads to a spectrum of psychological penalties.[7]

University life is a crucial stage in the improvement and preservation of mental health toward impartial adulthood. Emotional problems such as anxiety and depression can have a profound effect on the fitness and overall faculty performance of the students. The COVID-19 pandemic has drastically affected the education system in China, wherein the opening of all universities for the new semester has been postponed until further notice to control the epidemic. Many universities decided to suspend in-person classes and evacuate students in response to the intensifying concerns surrounding COVID-19. To ensure their safety, the students were instructed to be quarantined in the dormitories or private renting apartments when the disease outbreak began. As more universities are transitioning to remote learning after the spring break, some of the students are going through intellectual health issues due to the disruption of academic schedule and tutorial events [9]. For example, many postgraduate students had to cease their research projects, removing all the experimental animals from the laboratories. Moreover, disruption of their research projects and internships jeopardizes their study applications which would possibly extend their graduation, and undermine their competitiveness on the job market which may fuel anxiety among the students. Those who left their rented apartments, leaving all their belongings behind and went back home are still paying their monthly rents despite not living in China. Universities have delayed the plans to allow students to return to China which might make the students more worried about their future as they need to complete university graduation requirements before graduating. During the SARS outbreak, as many people suffered from poor sleep and short sleep periods due to anxious and depressive symptoms [10], [11] it is reasonable to assume that a higher exposure leads to much less sleep, which in turn increases the chance of intellectual illness. Based on a study published on the SARS epidemic, the longer the isolation, the greater the opportunity of psychological distress.[12] Therefore, it is indispensable to discover the relationship between the time spent in home-quarantine and intellectual sickness to perceive the impact of important epidemics or ailment outbreaks on international students. It is consequently fundamental to recognize the feasible relationships between the COVID-19 pandemic, sleep periods, and underlying intellectual ailments in the university student population. Such research would enhance the understanding of the requirement of psychological adjustment mechanisms wished to make sure the wide-spread well-being of the international students.

Thus, we conducted an online mental health survey for international students related to the COVID-19 outbreak to further understand the presence of psychological issues among these students while taking into account the potential differences based on gender, grade year, duration and status of quarantine, duration of sleep, worries about graduation, being able to go to school and presence or absence of a sense of security.

\section{Aims Of This Study}


The main aim of this study was to observe the effects of quarantine policy on the psychological health of international students. So that they can be screened, diagnosed, and treated effectively for the same. These students are the future of the health workforce who will contribute to the development of a healthy population in a country. Therefore, it was important to analyze whether mental health issues were affecting foreign international students during the COVID-19 outbreak. It was also imperative to study any discrepancies in these issues based on the parameters of gender, grade year, duration and status of quarantine, duration of sleep, worries about graduation, being able to go to school, and the presence or absence of a sense of security.

\section{Materials And Methods}

Study procedure

The target population comprised of international students from Central South University including undergraduates, Master's degree/postgraduate students, and Ph.D./doctoral students. The questionnaire was comprised of questions on demographic information, gender, grade year, duration and status of quarantine, duration of sleep, worries about graduation, being able to go to school, and the presence or absence of a sense of security.

The data was collected from students who have been unable to go to school since the COVID-19 outbreak, from January 25,2020 , to June 26,2020 . The survey was completed on the Chinese Star Survey website between 19th to 26th June, with the relevant smartphone link sent to the Xiangya WeChat international students group. These students were informed about the motive of the survey i.e to comprehend the effects of the COVID-19 epidemic on the mental health of international students.

\section{Depression}

Depression was assessed using the 9-item Patient Health Questionnaire-9 (PHQ-9), which is sensitive and specific, sufficient to screen adolescents with suspected depression.[10] Furthermore, the PHQ-9 is the most regularly used device designed for screening depression in primary care [11][12], [13], and is a 9item depression module from the full PHQ. The participants were requested to respond to the questions to consider the frequency of the specific symptoms that they felt during the quarantine period. The solutions were scored as follows: zero(0) point for not at all, one(1) point for several days, two(2) points for more than half of the days, and three(3) points for nearly every day. The score was scaled from 0-27 (0-4: without depressive symptoms, 5-9: with mild depression symptoms, 10-14: with moderate depression symptoms, 15-19: with moderate to severe depression symptoms, and 20-27: with severe depression symptoms) [11]. This scale has additionally been broadly used with Chinese populations and has validated brilliant psychometric properties [14].

Anxiety

Anxiety was assessed by the usage of the 7-item Generalized Anxiety Disorder-7 (GAD-7) scale, which has been used to consider the mental health status of people after the MERS outbreak [15]. The GAD-7 scale contains seven noticeably applicable questions chosen from 13 items (nine questions from the Diagnostic and Statistical Manual of Mental Disorder, 4th Edition, and four questions from the Anxiety Symptom Scale). For every item, the participants were asked about their frequency of experiencing each one of the emotions at some stage during their quarantine period for COVID-19. The answers were scored as follows: zero (0) point for not at all, one (1) point for several days, two(2) points for more than half of the days, and three(3) points for nearly every day. The score was scaled from 0-21 (0-4: without anxiety symptoms, 5-9: with mild anxiety symptoms, 10-14: with moderate anxiety symptoms, and 15-21: with severe anxiety symptoms) [15].

To figure out if STAI-Y2 TRAIT scores can be a predictive factor of depression or anxiety, all participants have been assessed with the State-Trait Anxiety Inventory (STAI). The STAI-Y consists of 40 self-report items, for both state and trait components. STAI-Y items are rated on a 4-point Likert scale. (STAIY1STATE) report the extent of their anxiety at particular moments, while (STAI-Y2TRAIT) indicate the intensity of their anxiety in general: both scores were computed in this study. Scores of each state- and trait-anxiety range from 20 to 80 , a higher score indicating greater anxiety. [16]

Quarantine

Students who lived in the dormitory have been in quarantine since January 25 which is still ongoing as of July 7 until further notice. Hence, they have been in quarantine for about 6 months now. Quarantine period was determined by the question: "How much time on average have you spent in quarantine from the outside since the COVID-19 outbreak and are you still in quarantine now?" According to the duration, participants were categorized into 5 groups: None, 1 month, 2 months, 3 months, 4 months, 5 months, and 6 months. According to the current situation, participants were categorized into two groups: still in quarantine and not in quarantine.

Sleep duration

Sleep length was determined by the question: "How much sleep you had on average every night over the past four weeks?" The participants were categorized into six groups based on their reported average sleep duration: $<6$ hours/night, $\geq 6$ to $<7$ hours/night, $\geq 7$ to $<8$ hours/night, $\geq 8$ to $<9$ hours/night, $\geq 9$ to $<10$ and $\geq 10$ hours/night [17] with $<6$ hours/night being seen as short sleep duration.[18]

Degree of worrying about graduation

The degree of worrying about graduation was determined from the question: "how much do you worry about graduation?" Participants were categorized into 4 groups: Not at all, a little, somewhat, and very much.

School Time 
To be able to go to school was determined by the question: "Can you go back to school/hospital to study now?" If you can, how long? Participants were categorized into 2 groups: Not at all, sometimes.

Sense of security

The presence or absence of a sense of security was determined by the question: "do u feel secure?" Participants were categorized into 4 groups: Not at all, a little, somewhat, and very.

\section{Ethical approval and consent}

The participants were informed that the motive of the survey was to comprehend the psychological effects of the COVID-19 epidemic on students and was conducted via an online WeChat notification before the investigation. Students who were willing to participate in the survey filled out the questionnaires. Online informed written consent was obtained from all participants at the beginning of the questionnaire. The present study was approved by the Medical Ethics Committee of Second Xiangya Hospital of Central South University (2020) of the National Examination Bureau Number (001)

\section{Statistical Analysis}

All statistical analyses were performed using the IBM SPSS Statistical Software (version 22). Counting data was presented in counts (the percentage of the total). The chi-square test was used to determine whether there were significant differences between the number of asymptomatic and symptomatic students, in terms of different genders, grade year, duration and status of quarantine, duration of sleep, worries about graduation, being able to go to school and presence or absence of a sense of security. The Kruskal-Wallis test was used to determine whether there were significant differences among the number of symptomatic (in varying degrees) students, in terms of different gender, grade year, duration and status of quarantine, duration of sleep, worries about graduation, being able to go to school and presence or absence of a sense of security. One-way ANOVA and t-test calculations were used to assess the differences in the State-Trait Anxiety between the subgroups which were stratified by different gender, grade year, duration and status of quarantine, duration of sleep, worries about graduation, being able to go to school and presence or absence of a sense of security. A P-value of $<0.05$ was considered statistically significant.

\section{Results}

285 students received the questionnaire and the response rate was $53.7 \%$. A total of 153 students enrolled in the survey, which consisted of 143 students who were not diagnosed with any mental disorders previously and 10 students who were previously diagnosed with one or the other kind of mental disorders. The present survey excluded the students who have previously suffered from mental disorders. Detailed information is presented in Table 1. A large proportion of respondents was found in the Master student group (63.6\%) घMale students group (67.8\%) and quarantine group (59.4\%). 
Table 1

Demographic characteristics of the participants in the survey.

\begin{tabular}{|c|c|}
\hline & Participants $(n=153)$ \\
\hline \multicolumn{2}{|c|}{ Diagnosed mental disorder before } \\
\hline No & 143 \\
\hline Yes(exclude) & 10 \\
\hline Age(y) & $28.66 \pm 4.1(20-40)$ \\
\hline \multicolumn{2}{|l|}{ University year } \\
\hline Undergraduate & $19(13.3 \%)$ \\
\hline Master & $91(63.6 \%)$ \\
\hline Doctor & $33(23.1 \%)$ \\
\hline \multicolumn{2}{|l|}{ Gender } \\
\hline Male & $97(67.8 \%)$ \\
\hline Female & $46(32.2 \%)$ \\
\hline \multicolumn{2}{|l|}{ Quarantine } \\
\hline Yes & $85(59.4 \%)$ \\
\hline No & $58(40.6 \%)$ \\
\hline \multicolumn{2}{|c|}{ The degree of worrying about graduation } \\
\hline Not at all & $44(30.8 \%)$ \\
\hline A little & $38(26.6 \%)$ \\
\hline Somewhat & $21(14.7 \%)$ \\
\hline Very much & $40(28.0 \%)$ \\
\hline \multicolumn{2}{|l|}{ Sleep duration } \\
\hline$<6$ hours/night & $34(23.8 \%)$ \\
\hline$\geq 6$ to $<7$ hours/night & $43(30.1 \%)$ \\
\hline$\geq 7$ to $<8$ hours/night & $35(24.5 \%)$ \\
\hline$\geq 8$ to $<9$ hours/night & $23(16.1 \%)$ \\
\hline$\geq 9$ to $<10$ & $3(2.1 \%)$ \\
\hline$\geq 10$ hours/night & $5(3.5 \%)$ \\
\hline \multicolumn{2}{|l|}{ School time } \\
\hline Zero & $99(69.2 \%)$ \\
\hline Some & $44(30.8 \%)$ \\
\hline \multicolumn{2}{|l|}{ Secure } \\
\hline Not at all & $17(11.9 \%)$ \\
\hline A little & $32(22.4 \%)$ \\
\hline Somewhat & $42(29.4 \%)$ \\
\hline Very much & $52(36.4 \%)$ \\
\hline \multicolumn{2}{|l|}{ PHQ-9 } \\
\hline 0-4 (asymptomatic) & $58(40.6 \%)$ \\
\hline 5-9 (mild) & $34(23.8 \%)$ \\
\hline 10-14 (moderate) & $32(22.4 \%)$ \\
\hline 15-19 (moderate to severe) & $9(6.3 \%)$ \\
\hline 20-27 (severe) & $10(7.0 \%)$ \\
\hline GAD-7 & \\
\hline
\end{tabular}

Page 5/13 


\begin{tabular}{|ll|}
\hline & Participants $(\mathbf{n}=153)$ \\
\hline $0-4$ (asymptomatic) & $89(62.2 \%)$ \\
\hline $5-9$ (mild) & $29(20.3 \%)$ \\
$10-14$ (moderate) & $12(8.4 \%)$ \\
\hline $15-21$ (severe) & $13(9.1 \%)$ \\
\hline STAl-Y1 STATE scores $(\mathrm{M} \pm$ SD) & $41.42 \pm 10.89$ \\
STAI-Y2 TRAIT scores $(\mathrm{M} \pm$ SD) & $41.85 \pm 11.13$ \\
\hline
\end{tabular}

Based on the results of the questionnaire, it was found that the prevalence of depression (defined as a total score of $\geq 5$ in the PHQ-9) was $59.4 \%$ and the prevalence of anxiety (defined as a total score of $\geq 5$ in the GAD-7) was $37.8 \%$. The majority of students who were in a depressed or anxious state were mild or moderate, $13.3 \%$ were in moderate to severe and severely depressed state and $9.1 \%$ were in a severe anxiety state.

Comparisons of neuropsychological features

As shown in Fig. 1 and Table 2 and Table 3, regarding the worrying about graduation in varying degrees, the PHQ-9 results revealed that there were 17(38.6\%) of the 44 students who did not worry about graduation at all, $23(60.5 \%)$ of the 38 students who worried about graduation a little, $14(66.7 \%)$ of the 21 students who worried about graduation somewhat, $31(77.5 \%)$ of the 40 students who worried about graduation very much were in a state of depression. Besides, the GAD-7 results revealed that $7(15.9 \%)$ of the 44 students who did not worry about graduation at all, $19 \otimes 50.0 \% \bigotimes$ of the 38 students who worried about graduation a little, $9 ₫ 42.9 \% \rrbracket$ of the 21 students who worried about graduation somewhat, $19 \varangle 47.5 \% \rrbracket$ of the 40 students who worried about graduation very much were in a state of anxiety. About feeling secure in varying degrees, the PHQ-9 results revealed that there were 11(64.7\%) of the 17 students who did not feel secure at all, 26(81.3\%) of the 32 students who felt a little secure, 27(64.3\%) of the 42 students who felt somewhat secure, 21 (40.4\%) of the 52 students who felt very much secure were in a state of depression. Also, the GAD-7 results revealed that 7(41.2\%) of the 17 students who did not feel secure at all, $22(68.8 \%)$ of the 32 students who felt a little secure, $17(40.5 \%)$ of the 42 students who felt somewhat secure, $8(15.4 \%)$ of the 52 students who felt very much secure were in a state of anxiety. Several factors contributed to the prevalence of depression including Sleep duration $(p=0.007)$, worrying about graduation in varying degrees $(p=0.003)$ and feeling secure in varying degrees $(p=0.002)$. Several factors contributed to the severity of depression including Sleep duration $(p=0.016)$, worrying about graduation in varying degrees $(p<0.001)$, School time $(p=0.039)$, and feeling secure in varying degrees $(<0.001)$. Several factors contributed to the prevalence of anxiety including worrying about graduation in varying degrees $(p=0.004)$ and feeling secure in varying degrees ( $<<0.001)$. Several factors contributed to the severity of anxiety including Sleep duration $(p=0.011)$, worrying about graduation in varying degrees $(p=0.001)$, and feeling secure in varying degrees $(p<0.001)$.

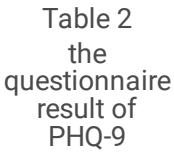




\begin{tabular}{|c|c|c|c|c|c|c|c|c|}
\hline PHQ-9 & Asymptomatic & Symptomatic & $\mathrm{P}$ & Mild & Moderate & Moderate to Severe & Severe & $\mathrm{P}$ \\
\hline & $(0-4)$ & $(\geq 5)$ & & $\otimes 5-9 \square$ & $(10-14)$ & $(15-19)$ & $(19-27)$ & \\
\hline Gender & & & 0.91 & & & & & 0.743 \\
\hline Male & $39(40.2 \%)$ & $58(59.8 \%)$ & & $25(25.8 \%)$ & $20(20.6 \%)$ & $8(8.2 \%)$ & $5(5.2 \%)$ & \\
\hline Female & $19(41.3 \%)$ & $27(58.7 \%)$ & & $9(19.6 \%)$ & $12(26.1 \%)$ & $1(2.2 \%)$ & $5(10.9 \%)$ & \\
\hline Degree & & & 0.110 & & & & & 0.163 \\
\hline Undergraduate & $4(21.1 \%)$ & $15(78.9 \%)$ & & $6(31.6 \%)$ & $5(26.3 \%)$ & $3 \otimes 15.8 \%)$ & $1 \otimes 5.3 \%)$ & \\
\hline Master & $42(46.2 \%)$ & $49(53.8 \%)$ & & $22 \llbracket 24.2 \%)$ & $16 \otimes 17.6 \% \square$ & $4 \rrbracket 4.4 \% \bigotimes$ & $7 \rrbracket 7.7 \% \bigotimes$ & \\
\hline Doctor & $12(36.4 \%)$ & $21(63.6 \%)$ & & $6 \rrbracket 18.2 \% \square$ & $11 \llbracket 33.3 \% \rrbracket$ & $2 \varangle 6.1 \% \rrbracket$ & $2 \searrow 6.1 \% \rrbracket$ & \\
\hline Quarantine & & & 0.856 & & & & & 0.942 \\
\hline Yes & $35 \rrbracket 41.2 \% \rrbracket$ & $50 \rrbracket 58.8 \% \rrbracket$ & & $18 \llbracket 21.2 \% \rrbracket$ & $19 \llbracket 22.4 \% \rrbracket$ & $7 \rrbracket 8.2 \% \rrbracket$ & $6 \otimes 7.1 \% \bigotimes$ & \\
\hline No & $23 \rrbracket 39.7 \% \rrbracket$ & $35 \rrbracket 60.3 \% \bigotimes$ & & $16 \llbracket 27.6 \% \square$ & $13 \llbracket 22.4 \% \square$ & $2 \searrow 3.4 \% \bigotimes$ & $4 \rrbracket 6.9 \% \rrbracket$ & \\
\hline Sleep duration & & & 0.007 & & & & & 0.016 \\
\hline$<6$ hours/night & $7 \rrbracket 20.6 \% \rrbracket$ & $27 ه 79.4 \% \bigotimes$ & & $11 \llbracket 32.4 \% \bigotimes$ & $9(26.5 \%)$ & $3(8.8 \%)$ & $4(11.8 \%)$ & \\
\hline$\geq 6$ hours/night & $51 \rrbracket 46.8 \% \rrbracket$ & $58 \rrbracket 53.2 \% \rrbracket$ & & $23 \rrbracket 21.1 \% \rrbracket$ & $23 \llbracket 21.1 \% \square$ & $6 \rrbracket 5.5 \% \rrbracket$ & $6 \rrbracket 5.5 \% \rrbracket$ & \\
\hline worry & & & 0.003 & & & & & $<0.001$ \\
\hline Not at all & $27(61.4 \%)$ & $17(38.6 \%)$ & & $13(29.5 \%)$ & $2(4.5 \%)$ & $2(4.5 \%)$ & $0(0.0 \%)$ & \\
\hline A little & $15(39.5 \%)$ & $23(60.5 \%)$ & & $5(13.2 \%)$ & $12(31.6 \%)$ & $2(5.3 \%)$ & $4(10.5 \%)$ & \\
\hline Somewhat & $7(33.3 \%)$ & $14(66.7 \%)$ & & $5(23.8 \%)$ & $7(33.3 \%)$ & $1(4.8 \%)$ & $1(4.8 \%)$ & \\
\hline Very much & $9(22.5 \%)$ & $31(77.5 \%)$ & & $11(27.5 \%)$ & $11(27.5 \%)$ & $4(10.0 \%)$ & $5(12.5 \%)$ & \\
\hline School time & & & 0.057 & & & & & 0.039 \\
\hline Zero & $35(35.4 \%)$ & $64(64.6 \%)$ & & $26(26.3 \%)$ & $24(24.2 \%)$ & $6(6.1 \%)$ & $8(8.1 \%)$ & \\
\hline Some & $23(52.3 \%)$ & $21(47.7 \%)$ & & $8(18.2 \%)$ & $8(18.2 \%)$ & $3(6.8 \%)$ & $2(4.5 \%)$ & \\
\hline Secure & & & 0.002 & & & & & $<0.001$ \\
\hline Not at all & $6(35.3 \%)$ & $11(64.7 \%)$ & & $3(17.6 \%)$ & $3(17.6 \%)$ & $0(0.0 \%)$ & $5(29.4 \%)$ & \\
\hline A little & $6(18.8 \%)$ & $26(81.3 \%)$ & & $7(21.9 \%)$ & $11(34.4 \%)$ & $6(18.8 \%)$ & $2(6.3 \%)$ & \\
\hline Somewhat & $15(35.7 \%)$ & $27(64.3 \%)$ & & $10(23.8 \%)$ & $12(28.6 \%)$ & $3(7.1 \%)$ & $2(4.8 \%)$ & \\
\hline Very much & $31(59.6 \%)$ & $21(40.4 \%)$ & & $14(26.9 \%)$ & $6(11.5 \%)$ & $0(0.0 \%)$ & $1(1.9 \%)$ & \\
\hline
\end{tabular}


Table 3

the questionnaire result of GAD-7

\begin{tabular}{|c|c|c|c|c|c|c|c|c|}
\hline PHQ-9 & Asymptomatic & Symptomatic & $\mathbf{P}$ & Mild & Moderate & Moderate to Severe & Severe & $\mathbf{P}$ \\
\hline & $(0-4)$ & $(\geq 5)$ & & $(5-9)$ & $(10-14)$ & $(15-19)$ & $(19-27)$ & \\
\hline Gender & & & 0.91 & & & & & 0.743 \\
\hline Male & $39(40.2 \%)$ & $58(59.8 \%)$ & & $25(25.8 \%)$ & $20(20.6 \%)$ & $8(8.2 \%)$ & $5(5.2 \%)$ & \\
\hline Female & $19(41.3 \%)$ & $27(58.7 \%)$ & & $9(19.6 \%)$ & $12(26.1 \%)$ & $1(2.2 \%)$ & $5(10.9 \%)$ & \\
\hline Degree & & & 0.110 & & & & & 0.163 \\
\hline Undergraduate & $4(21.1 \%)$ & $15(78.9 \%)$ & & $6(31.6 \%)$ & $5(26.3 \%)$ & $3(15.8 \%)$ & $1(5.3 \%)$ & \\
\hline Master & $42(46.2 \%)$ & $49(53.8 \%)$ & & $22(24.2 \%)$ & $16(17.6 \%)$ & $4(4.4 \%)$ & $7(7.7 \%)$ & \\
\hline Doctor & $12(36.4 \%)$ & $21(63.6 \%)$ & & $6(18.2 \%)$ & 11(33.3\%) & $2(6.1 \%)$ & $2(6.1 \%)$ & \\
\hline Quarantine & & & 0.856 & & & & & 0.942 \\
\hline Yes & $35(41.2 \%)$ & $50(58.8 \%)$ & & $18(21.2 \%)$ & $19(22.4 \%)$ & $7(8.2 \%)$ & $6(7.1 \%)$ & \\
\hline No & $23(39.7 \%)$ & $35(60.3 \%)$ & & $16(27.6 \%)$ & $13(22.4 \%)$ & $2(3.4 \%)$ & $4(6.9 \%)$ & \\
\hline Sleep duration & & & 0.007 & & & & & 0.016 \\
\hline$<6$ hours/night & $7(20.6 \%)$ & $27(79.4 \%)$ & & $11(32.4 \%)$ & $9(26.5 \%)$ & $3(8.8 \%)$ & $4(11.8 \%)$ & \\
\hline$\geq 6$ hours/night & $51(46.8 \%)$ & $58(53.2 \%)$ & & $23(21.1 \%)$ & $23(21.1 \%)$ & $6(5.5 \%)$ & $6(5.5 \%)$ & \\
\hline worry & & & 0.003 & & & & & $<0.001$ \\
\hline Not at all & $27(61.4 \%)$ & $17(38.6 \%)$ & & $13(29.5 \%)$ & $2(4.5 \%)$ & $2(4.5 \%)$ & $0(0.0 \%)$ & \\
\hline A little & $15(39.5 \%)$ & $23(60.5 \%)$ & & $5(13.2 \%)$ & $12(31.6 \%)$ & $2(5.3 \%)$ & $4(10.5 \%)$ & \\
\hline Somewhat & $7(33.3 \%)$ & $14(66.7 \%)$ & & $5(23.8 \%)$ & 7(33.3\%) & $1(4.8 \%)$ & $1(4.8 \%)$ & \\
\hline Very much & $9(22.5 \%)$ & $31(77.5 \%)$ & & $11(27.5 \%)$ & $11(27.5 \%)$ & $4(10.0 \%)$ & $5(12.5 \%)$ & \\
\hline School time & & & 0.057 & & & & & 0.039 \\
\hline Zero & $35(35.4 \%)$ & $64(64.6 \%)$ & & $26(26.3 \%)$ & $24(24.2 \%)$ & $6(6.1 \%)$ & $8(8.1 \%)$ & \\
\hline Some & $23(52.3 \%)$ & $21(47.7 \%)$ & & $8(18.2 \%)$ & $8(18.2 \%)$ & $3(6.8 \%)$ & $2(4.5 \%)$ & \\
\hline Secure & & & 0.002 & & & & & $<0.001$ \\
\hline Not at all & $6(35.3 \%)$ & $11(64.7 \%)$ & & $3(17.6 \%)$ & $3(17.6 \%)$ & $0(0.0 \%)$ & $5(29.4 \%)$ & \\
\hline A little & $6(18.8 \%)$ & 26(81.3\%) & & $7(21.9 \%)$ & $11(34.4 \%)$ & $6(18.8 \%)$ & $2(6.3 \%)$ & \\
\hline Somewhat & $15(35.7 \%)$ & $27(64.3 \%)$ & & $10(23.8 \%)$ & $12(28.6 \%)$ & $3(7.1 \%)$ & $2(4.8 \%)$ & \\
\hline Very much & $31(59.6 \%)$ & $21(40.4 \%)$ & & $14(26.9 \%)$ & $6(11.5 \%)$ & $0(0.0 \%)$ & $1(1.9 \%)$ & \\
\hline
\end{tabular}

Average distribution of State-Trait Anxiety

As shown in Table 4, the scores of the State-Trait Anxiety Inventory scale were both significantly enhanced as compared to the students who sleep more than 6 hours/night group $(p=0.008$ and 0.007$)$. Similarly, the scores of the State-Trait Anxiety Inventory scale were both increased when compared with the students who worried less about the graduation group and the students who fell more secure group $(p<0.001$ and $P<0.001, p<0.001$ and $P<0.001$, respectively). 
Table 4

the questionnaire result of State-Trait Anxiety Inventory

\begin{tabular}{|c|c|c|c|c|c|c|c|}
\hline GAD-7 & Asymptomatic & Symptomatic & $\mathbf{P}$ & Mild & Moderate & Severe & $\mathbf{P}$ \\
\hline & $(0-4)$ & $(\geq 5)$ & & $(5-9)$ & $(10-14)$ & $(15-21)$ & \\
\hline Gender & & & 0.180 & & & & 0.245 \\
\hline Male & $64(66.0 \%)$ & $33(34.0 \%)$ & & 19(19.6\%) & $7(7.2 \%)$ & $7(7.2 \%)$ & \\
\hline Female & $25(54.3 \%)$ & $21(45.7 \%)$ & & $10(21.7 \%)$ & $5(10.9 \%)$ & $6(13.0 \%)$ & \\
\hline Degree & & & 0.291 & & & & 0.115 \\
\hline Undergraduate & $10(52.6 \%)$ & $9(47.4 \%)$ & & $4(21.1 \%)$ & $3(15.8 \%)$ & $2(10.5 \%)$ & \\
\hline Master & $61(67.0 \%)$ & $30(33.0 \%)$ & & 18(19.8\%) & $5(5.5 \%)$ & $7(7.7 \%)$ & \\
\hline Doctor & $18(54.5 \%)$ & $15(45.5 \%)$ & & $7(21.2 \%)$ & $4(12.1 \%)$ & $4(12.1 \%)$ & \\
\hline Quarantine & & & 0.751 & & & & 0.811 \\
\hline Yes & $52(61.2 \%)$ & $33(38.8 \%)$ & & $16(18.8 \%)$ & $9(10.6 \%)$ & $8(9.4 \%)$ & \\
\hline No & $37(63.8 \%)$ & $21(36.2 \%)$ & & $13(22.4 \%)$ & $3(5.2 \%)$ & $5(8.6 \%)$ & \\
\hline Sleep duration & & & 0.200 & & & & 0.011 \\
\hline$<6$ hours/night & $18(52.9 \%)$ & $16(47.1 \%)$ & & $4(11.8 \%)$ & $5(14.7 \%)$ & $7(20.6 \%)$ & \\
\hline$\geq 6$ hours/night & $71(65.1 \%)$ & $38(34.9 \%)$ & & $25(22.9 \%)$ & $7(6.4 \%)$ & $6(5.5 \%)$ & \\
\hline Worry & & & 0.004 & & & & 0.001 \\
\hline Not at all & $37(84.1 \%)$ & $7(15.9 \%)$ & & $5(11.4 \%)$ & $2(4.5 \%)$ & $0(0.0 \%)$ & \\
\hline A little & $19(50.0 \%)$ & $19(50.0 \%)$ & & $11(28.9 \%)$ & $4(10.5 \%)$ & $4(10.5 \%)$ & \\
\hline Somewhat & $12(57.1 \%)$ & $9(42.9 \%)$ & & $7(33.3 \%)$ & $1(4.8 \%)$ & $1(4.8 \%)$ & \\
\hline Very much & $21(52.5 \%)$ & $19(47.5 \%)$ & & $6(15.0 \%)$ & $5(12.5 \%)$ & $8(20.0 \%)$ & \\
\hline School time & & & 0.546 & & & & 0.391 \\
\hline Zero & $60(60.6 \%)$ & $39(39.4 \%)$ & & $21(21.2 \%)$ & $8(8.1 \%)$ & $10(10.1 \%)$ & \\
\hline Some & $29(65.9 \%)$ & $15(34.1 \%)$ & & $8(18.2 \%)$ & $4(9.1 \%)$ & $3(6.8 \%)$ & \\
\hline Secure & & & $<0.001$ & & & & $<0.001$ \\
\hline Not at all & $10(58.8 \%)$ & $7(41.2 \%)$ & & $2(11.8 \%)$ & $1(5.9 \%)$ & $4(23.5 \%)$ & \\
\hline A little & $10(31.3 \%)$ & $22(68.8 \%)$ & & $11(34.4 \%)$ & $7(21.9 \%)$ & $4(12.5 \%)$ & \\
\hline Somewhat & $25(59.5 \%)$ & $17(40.5 \%)$ & & $9(21.4 \%)$ & $4(9.5 \%)$ & $4(9.5 \%)$ & \\
\hline Very much & $44(84.6 \%)$ & $8(15.4 \%)$ & & $7(13.5 \%)$ & $0(0.0 \%)$ & $1(1.9 \%)$ & \\
\hline
\end{tabular}

linear regression model

As shown in Table 5, Higher the Patient Health Questionnaire-9 score and higher Generalized Anxiety Disorder-7 score and higher STAI-Y1 STATE scores were associated with higher STAI-Y2 TRAIT scores, all p values were smaller than 0.001 . 
Table 5

linear regression model of Generalized Anxiety Disorder-7 (GAD-7) SCORE, Patient Health Questionnaire-9 (PHQ-9) SCORE, and STAI-Y1-Y1 scores

\begin{tabular}{|c|c|c|c|c|c|c|}
\hline & STAI-Y1 STATE scores & $T / f$ & $\mathbf{P}$ & STAI-Y2 TRAIT scores & $T / f$ & $\mathbf{P}$ \\
\hline & $(\mathrm{M} \pm \mathrm{SD})$ & & & $(\mathrm{M} \pm \mathrm{SD})$ & & \\
\hline Gender & & 0.629 & 0.531 & & .191 & 0.849 \\
\hline Male & $41.8144 \pm 10.60791$ & & & $41.9691 \pm 10.70675$ & & \\
\hline Female & $40.5870 \pm 11.52500$ & & & $41.5870 \pm 12.09330$ & & \\
\hline Degree & & 1.352 & 0.262 & & .510 & 0.601 \\
\hline Undergraduate & $43.0526 \pm 7.79939$ & & & $43.4211 \pm 8.07132$ & & \\
\hline Master & $40.2967 \pm 11.47412$ & & & $41.1429 \pm 11.66054$ & & \\
\hline Doctor & $43.5758 \pm 10.55353$ & & & $42.8788 \pm 11.25488$ & & \\
\hline Quarantine & & -0.776 & 0.439 & & -0.151 & 0.880 \\
\hline Yes & $40.8353 \pm 11.03549$ & & & $41.7294 \pm 11.54741$ & & \\
\hline No & $42.2759 \pm 10.69972$ & & & $42.0172 \pm 10.58548$ & & \\
\hline Sleep duration & & 2.706 & 0.008 & & 2.729 & 0.007 \\
\hline$<6$ hours/night & $45.7353 \pm 10.58389$ & & & $46.2941 \pm 11.12063$ & & \\
\hline$\geq 6$ hours/night & $40.0734 \pm 10.67162$ & & & $40.4587 \pm 10.81283$ & & \\
\hline Worry & & 10.844 & $<0.001$ & & 8.500 & $<0.001$ \\
\hline Not at all & $34.4545 \pm 8.34839$ & & & $35.8182 \pm 9.31434$ & & \\
\hline A little & $43.4474 \pm 8.58880$ & & & $42.6053 \pm 10.18090$ & & \\
\hline Somewhat & $44.0952 \pm 11.70429$ & & & $43.2857 \pm 10.62611$ & & \\
\hline Very much & $45.7500 \pm 11.51309$ & & & $47.0000 \pm 11.36797$ & & \\
\hline School time & & 1.803 & 0.074 & & 1.293 & 0.198 \\
\hline No at all & $42.5051 \pm 10.44067$ & & & $42.6465 \pm 10.85462$ & & \\
\hline Some & $38.9773 \pm 11.57883$ & & & $40.0455 \pm 11.65184$ & & \\
\hline Secure & & / & $<0.001$ & & 20.184 & $<0.001$ \\
\hline Not at all & $50.7647 \pm 13.11740$ & & & $47.6471 \pm 12.09308$ & & \\
\hline A little & $47.8438 \pm 6.48626$ & & & $48.2188 \pm 7.44760$ & & \\
\hline Somewhat & $43.3571 \pm 8.70890$ & & & $44.3571 \pm 9.81244$ & & \\
\hline Very much & $32.8462 \pm 7.50786$ & & & $34.0000 \pm 9.12441$ & & \\
\hline \multirow[t]{2}{*}{ Factor } & STAI-Y2 TRAIT scores & & & & & \\
\hline & $R$ square $P$ & & & & & \\
\hline$P H Q-9$ & 0.364 & $<0.001$ & & & & \\
\hline$G A D-7$ & 0.454 & $<0.001$ & & & & \\
\hline STAI-Y1-Y1 scores & 0.702 & $<0.001$ & & & & \\
\hline
\end{tabular}

Table 1 |

GAD-7, Generalized Anxiety Disorder-7; PHQ-9, Patient Health Questionnaire-9.

Figure 1.

Table 21

Table 3|

Table 4

Table 5| 


\section{Discussion:}

Studies have cautioned that public health emergencies can have many psychological consequences on university students, which can be expressed as anxiety, fear, and worry, among others.[19]

The main aim of this study was to observe the effects of quarantine on sleep habits, mental health status (anxiety and depression), and psychological consequences on international university students studying at Central South University, Changsha approximately 6 months after the COVID-19 outbreak.

Although imposing confinement is an effective measure to control the widespread of infectious disease, our results suggest that it also leads to fear, anxiety, and depression, and has negative psychological impacts on international students. The results of our study show that international university students have increased anxiety and depressive symptoms during this COVID-19 outbreak. Recent studies have similarly shown that COVID-19 affects mental health outcomes such as anxiety, depression, and post-traumatic stress symptoms.[20]-[22]

Anxiousness among International university students about COVID-19 may have been associated with the impact of the virus on their research [23]and future employment [24]. On the other hand, the nervousness among students can also have been brought about by the way of progressively growing distances between humans ensuing from the quarantine. It is known that anxiety disorders are more likely to occur and worsen in the absence of interpersonal communication[25], [26] but in our present study, no significant differences were found between the students in quarantine and those who were not in quarantine. We assumed that the prolonged time of isolation and the associated consequences might induce depression and anxiety among these students. However, longer dormitory quarantine (around 6 months) was not found to be associated with anxiety or depression, this might be because all the students were already used to this kind of a situation as they are mostly indoors using all kinds of technologies and enjoying high-quality internet.

Regarding the sleep duration there is a robust affiliation between short sleep duration and depression in our results, which can also be assumed that sleep length mediated mental health problems, mental stress may additionally deteriorate sleep duration, which may then give rise to depression or PTSD, which is consistent with previous SARs studies.[27] Other sleep parameters or different variables may additionally have acted as mediators; however, this requires additional study.

The results of the present study indicated that six months out of school made students worry about graduation which could affect students' mental health. The possible reason could be that these students were under a lot of academic pressure, the uncertainty about the pandemic effect may have increased their worry about graduating, finding a job, or enrolling in further studies. This additional stress combined with the effects of the pandemic could be seen to be a dose-effect response that identifies a potential risk for developing mental health problems. Therefore, to ease their concerns, subsequent psychological interventions need to center of attention on strengthening psychological counseling and emotional remedy for graduating students.

students have been unable to go to school for many months now which has already made some students anxious, so allowing students to get back to their academic routine may not make students less anxious immediately but it might make students less depressed. In mainland China and Hong Kong, all primary and secondary schools had been closed, and universities have been both instructed to be suspended till March 2020 and may have been using distant learning strategies.[28] These measures, without doubt, have a particular effect on the training and the mental health of students.

It has been quite a long time since the pandemic is under control in Changsha, yet there were still some new patients with COVID-19 in Beijing and the situation was still severe abroad when we did our survey, so some students still feel insecure. This insecurity caused by this pandemic has deeply affected students' mental health. The COVID-19-related stressors, which include effects on daily life, and cause academic delays, were positively associated with anxiety symptoms of international students during the pandemic.

\section{LIMITATIONS}

Despite the importance of the findings, this study had several limitations. Firstly, as the study was focused on international students, the results may not apply to other adults or the general population. Secondly, online self-assessments and non-rigorous random sampling were made through semi-structured diagnostic interviews, and all results were self-assessed, which may introduce bias through the reporter effect. Further research will have to use a greater expert method as stipulations permit. Thirdly, the number of students who participated in the survey was small, and the viable motive is the voluntary nature of the survey. Hence, some students opted not to participate.

\section{Conclusion:}

International students, in a foreign land (China), are a distinctive group that ought to no longer be overlooked during the quarantine period. The present study is one of the few types of research that investigated the mental health condition prerequisites of international students at some point in the COVID-19 pandemic. As international students were found to have high rates of depression and anxiety, the existing findings imply that universities need to take measures to prevent, identify, and deal with the mental health problems of students. Apart from offering online courses for the students, other forms of academic competition such as (games, essays, plays) should be launched, which could make the life of students more exciting, and teachers should pay more attention to students with moderate or severe depression and/or anxiety. Helping them resolve the issues they come across is additionally a way to relieve anxiety and stress. Nevertheless, if the signs of a student are too extreme to be resolved by the teacher, expert prognosis and therapy have to be implemented. Therefore, universities need to consider planning for acute and long-term psychological services for international students.

\section{Declarations}


Ethics Approval and Consent to Participate: The present study was approved by the Medical Ethics Committee of Second Xiangya Hospital of Central South University (2020) of the National Examination Bureau Number (001). Online informed written consent was obtained from all participants at the beginning of the questionnaire

Consent for publication: Not applicable.

Availability of Data and Material: The datasets generated and/or analyzed during the current study are not publicly available due [REASON WHY DATA ARE NOT PUBLIC] but are available from the corresponding author on reasonable request.

Competing Interests: The authors declare that they have no competing interests.

Funding: This work has been supported by the

Department of Psychiatry, and National Clinical Research Center for Mental Disorders, The Second Xiangya Hospital of Central South University, Changsha 41C

Authors' Contributions: K.H and F.W contributed to the conception of the study. K.H and F.W were the major contributors to the writing of the manuscript. K.H and F.W performed the data analysis. K.H and F.W contributed to the interpretation and discussion of the results of the analysis. All authors have read and approved the final manuscript.

Acknowledgment The authors wish to thank all participants from Central South University Changsha, China

\section{References}

1. Zhu N, et al., "A novel coronavirus from patients with pneumonia in China, 2019," N. Engl. J. Med., 2020.

2. Li Q, et al., "Early transmission dynamics in Wuhan, China, of novel coronavirus-infected pneumonia," N. Engl. J. Med., 2020.

3. Li HY, Cao H, Leung DYP, Mak YW. The Psychological Impacts of a COVID-19 Outbreak on College Students in China: A Longitudinal Study. Int J Environ Res Public Health. 2020;17(11):3933.

4. Tang W, et al. Prevalence and correlates of PTSD and depressive symptoms one month after the outbreak of the COVID-19 epidemic in a sample of homequarantined Chinese university students. J Affect Disord. 2020;274:1-7. doi:10.1016/j.jad.2020.05.009.

5. Plexousakis SS, Kourkoutas E, Giovazolias T, Chatira K, Nikolopoulos D. School bullying and post-traumatic stress disorder symptoms: the role of parental bonding. Front public Heal. 2019;7:75.

6. Schwartz RM, Rasul R, Gargano LM, Lieberman-Cribbin W, Brackbill RM, Taioli E. Examining associations between Hurricane Sandy exposure and posttraumatic stress disorder by community of residence. J Trauma Stress. 2019;32(5):677-87.

7. Liu N, et al., "Prevalence and predictors of PTSS during COVID-19 outbreak in China hardest-hit areas: Gender differences matter," Psychiatry Res., p. 112921, 2020.

8. Van Bortel T, et al. Psychosocial effects of an Ebola outbreak at individual, community and international levels. Bull World Health Organ. 2016;94(3):210.

9. Agnew M, Poole H, Khan A. Fall break fallout: Exploring student perceptions of the impact of an autumn break on stress. Student Success. 2019;10(3):45.

10. Borghero F, Martínez V, Zitko P, Vöhringer PA, Cavada G, Rojas G. Tamizaje de episodio depresivo en adolescentes. Validación del instrumento PHQ-9. Rev Med Chil. 2018;146(4):479-86.

11. Kroenke K, Spitzer RL, Williams JBW. The PHQ-9.pdf. J Gen Intern Med. 2001;16:606-13. doi:10.1046/j.1525-1497.2001.016009606.x.

12. Levis B, Benedetti A, Thombs BD, "Accuracy of Patient Health Questionnaire-9 (PHQ-9) for screening to detect major depression: individual participant data meta-analysis," bmj, vol. 365, 2019.

13. Spitzer RL, Kroenke K, Williams JBW, Group PHQPCS. Validation and utility of a self-report version of PRIME-MD: the PHQ primary care study. Jama. 1999;282(18):1737-44.

14. Wang W, et al. Reliability and validity of the Chinese version of the Patient Health Questionnaire (PHQ-9) in the general population. Gen Hosp Psychiatry. 2014;36(5):539-44.

15. Jeong H, et al, “H.(2016)," Ment. Heal. status people Isol. due to Middle East Respir. Syndr. Epidemiol. Heal., vol. 38, p. e2016048.

16. Spielberger CD. "Manual for the State-Trait Anxiety Inventory STAI (form Y)(' self-evaluation questionnaire')," 1983.

17. Swinkels CM, Ulmer CS, Beckham JC, Buse N, Workgroup VAM-AMR, Calhoun PS. The association of sleep duration, mental health, and health risk behaviors among US Afghanistan/Iraq era veterans. Sleep. 2013;36(7):1019-25.

18. Sun Y, Shi L, Bao Y, Sun Y, Shi J, Lu L. The bidirectional relationship between sleep duration and depression in community-dwelling middle-aged and elderly individuals: evidence from a longitudinal study. Sleep Med. 2018;52:221-9.

19. Mei SL, Yu JX, He BW, Li JY. Psychological investigation of university students in a university in Jilin Province. Med Soc (Berkeley). 2011;24(05):84-6.

20. Cao W, et al., "The psychological impact of the COVID-19 epidemic on college students in China," Psychiatry Res., p. 112934, 2020.

21. Wang Y, Di Y, Ye J, Wei W. "Study on the public psychological states and its related factors during the outbreak of coronavirus disease 2019 (COVID-19) in some regions of China," Psychol. Health Med., pp. 1-10, 2020.

22. Ahmed MZ, Ahmed O, Aibao Z, Hanbin S, Siyu L, Ahmad A. "Epidemic of COVID-19 in China and associated Psychological Problems," Asian J. Psychiatr., p. $102092,2020$.

23. Cornine A. Reducing nursing student anxiety in the clinical setting: An integrative review. Nurs Educ Perspect. 2020;41(4):229-34.

Page $12 / 13$ 
24. Wang C, Horby PW, Hayden FG, Gao GF. A novel coronavirus outbreak of global health concern. Lancet. 2020;395(10223):470-3.

25. Kmietowicz Z. "Rules on isolation rooms for suspected covid-19 cases in GP surgeries to be relaxed." British Medical Journal Publishing Group, 2020.

26. Xiao C. A novel approach of consultation on 2019 novel coronavirus (COVID-19)-related psychological and mental problems: structured letter therapy. Psychiatry Investig. 2020;17(2):175.

27. Johal SS. "Psychosocial impacts of quarantine during disease outbreaks and interventions that may help to relieve strain.," 2009.

28. Kwok KO, Wong V, Wei VWI, Wong SYS, Tang JW-T. Novel coronavirus (2019-nCoV) cases in Hong Kong and implications for further spread. J Infect. 2020;80(6):671-93.

\section{Figures}
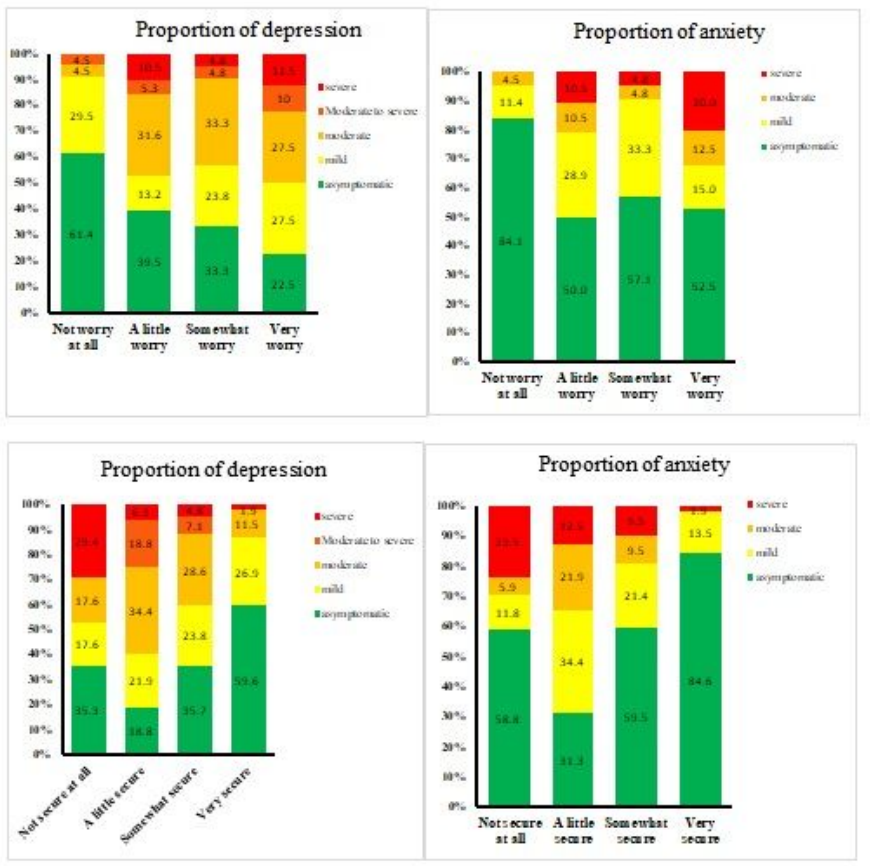

Figure 1

Comparisons of neuropsychological features between groups. The proportion of depression and anxiety in students worried about graduation in different degree group and the students who feel secure in different degree group. Colors indicate the different severities of neuropsychological status. 